\title{
Comparative karyotype analysis in diploid and triploid Dolichoplana carvalhoi (Tricladida, Terricola, Rhynchodemidae) from Brazil
}

\author{
Luciana Alvarez ${ }^{1}$ and Eunice Judith Cardoso de Almeida ${ }^{2}$ \\ ${ }^{1}$ Universidade de Santo Amaro, São Paulo, SP, Brazil. \\ ${ }^{2}$ Departamento de Genética e Biologia Evolutiva, Instituto de Biociências, Universidade de São Paulo, \\ São Paulo, SP, Brazil.
}

\begin{abstract}
In this work, we present cytogenetic data for the land planarian Dolichoplana carvalhoi. Two different karyotypes, one diploid ( $2 n=2 x=14$ chromosomes) and one triploid ( $2 n=3 x=21$ chromosomes), corresponding to two morphological body patterns, are described. Chromosomes from regenerating blastema were studied after routine Giemsa staining and CBG banding. Our analyses revealed heteromorphisms in chromosomes 2, 3 and 4 of the diploid karyotype and in chromosomes 1,3 and 7 of the triploid karyotype. Further studies are needed in order to determine if the two morphological patterns of $D$. carvalhoi represent distinct species.
\end{abstract}

Key words: land planarians, Dolichoplana carvalhoi, cytogenetics, triploidy, heteromorphisms, C-bands.

Received: August 4, 2006; Accepted: November 7, 2006.

\section{Introduction}

Planarians (Platyhelminthes, Seriata, Tricladida) are hermaphrodite, free-living and primarily carnivorous flatworms. They have remarkable capacity of regeneration. Nowadays, the suborder Tricladida is divided into four infraorders: Cavernicola, constituted by a group of five freshwater species, four of them living in caves; Maricola, to which sea planarians pertain; Paludicola, represented by freshwater planarians; Terricola, to which land planarians pertain.

A large number of numeric chromosome alterations, specially polyploidies, have been reported in Paludicola contrasting with the reduced chromosome variability observed in Cavernicola, Maricola and Terricola.

About 20 out of 80 freshwater species cytogenetically studied showed one or more types of polyploid cells. Triploidy has already been reported in the following Paludicola species: Dugesia benazzii (Benazzi-Lentati, 1966), D. brigantii (Puccinelli and Benazzi, 1985), D. gonocephala (De Vries, 1986), D. iberica (Gourbault, 1981), D. japonica japonica (Tamura, 1986), D. j. ryukyuensis (Oki et al, 1981), D. subtentaculata (De Vries, 1986), D. tigrina (Ribas et al, 1989), Phagocata vitta (Dahm, 1964), Polycelis auriculata (Teshirogi et al, 1991)

Send correspondence to Eunice Judith Cardoso de Almeida. Departamento de Genética e Biologia Evolutiva, Instituto de Biociências, Universidade de São Paulo, Rua do Matão 277, 05508-090 São Paulo, SP, Brazil. E-mail: eunicejudith@ terra.com.br and P. tenuis (Le Moigne, 1962). In Cavernicola, the only case of triploidy was described in Rhodax sp (Kawakatsu et al., 1985) and no numeric chromosome variation has been detected in Maricola so far.

In contrast to the large number of cytogenetic studies performed in freshwater planarians, only 16 land species have already been analyzed. Only three out of the 206 species of Rhynchodemidae have been cytogenetically studied: Microplana mahnerti, with $2 \mathrm{n}=10$ chromosomes (Minelli, 1977), Microplana terrestris, with $2 \mathrm{n}=6$ chromosomes (Ball and De Vries, 1983) and Platydemus manokwari, with $2 \mathrm{n}=12$ chromosomes (Oki et al., 1988).

Polyploid cells were found in two Terricola species: Geoplana burmeisteri and Pasipha pasipha (Garcia et al., 1998; Alvarez and Almeida, 2002). Specimens of Microplana terrestris with aneuploid cells have been described (Ball and De Vries, 1983).

In the present study, the karyotypes and distribution patterns of constitutive heterochromatin of the land planarian Dolichoplana carvalhoi are described for the first time. The specimens studied were collected in Brazil, where this species was introduced (Froehlich, 1967). The analyzed specimens presented two morphological patterns, corresponding to diploid and triploid karyotypes. Heteromorphisms were found in both kinds of karyotypes and this is the first report of triploidy for a land planarian species. 


\section{Materials and Methods}

Specimens of $D$. carvalhoi with two different patterns of body morphology were cytogenetically analyzed. The individuals of type 1 pattern showed five brownish dorsal stripes, with only one internal stripe. The specimens of type 2 had the same pattern reported in the original description of the species (Corrêa, 1947). They had three pairs of dorsal stripes. The internal pair was reddish and thinner than both the middle and the external stripes, which were similar in width and brownish. Eight of the twelve specimens collected in different regions of São Paulo State were of the morphological pattern 1 , whereas four were of pattern 2 (Table 1).

Five pattern 1 specimens collected in the city of São Paulo asexually produced two individuals each, totaling 13 individuals with pattern 1 . One pattern 2 individual collected in the city of São Paulo asexually originated four individuals. Thus, a total of seven animals with pattern 2 were studied. Two pattern 1 specimens had gonopores, whereas no pattern 2 specimen showed this structure.

Mitotic chromosome preparations from regenerating blastema cells were obtained by the air-drying technique as previously described (Almeida et al., 1991). Metaphase chromosomes were analyzed after Giemsa staining, and C-banding was performed according to Sumner (1972). Karyometric analyses were performed and chromosomes were morphologically classified according to Levan et al. (1964).

\section{Results}

\section{Karyotype of morphotype 1}

A total of 365 mitotic metaphases obtained from 17 regenerating blastemas of 13 pattern 1 individuals were analyzed. The karyotype showed $2 \mathrm{n}=2 \mathrm{x}=14$ chromosomes and comprised five metacentric (1, 4 to 7$)$, one submetacentric (2) and one subtelocentric (3) chromosome pairs (Table 2, Figure 1a).

The C-banding patterns revealed the presence of constitutive heterochromatin in the pericentromeric regions of all chromosomes and also in telomeric and interstitial positions in some of them. All the specimens analyzed showed C-banding heteromorphisms in chromosome pairs 2, 3 and 4. The pericentromeric block of heterochromatin is clearly larger in chromosomes $2 \mathrm{a}$ and $4 \mathrm{a}$ than in chromosomes $2 \mathrm{~b}$ and $4 \mathrm{~b}$. Chromosome $2 \mathrm{~b}$ showed a telomeric and an inter-

Table 1 - Collection sites of Dolichoplana carvalhoi specimens.

\begin{tabular}{lcc}
\hline Cities & \multicolumn{2}{c}{ Number of specimens of morphological patterns } \\
\cline { 2 - 3 } & $1(2 \mathrm{n}=2 \mathrm{x}=14)$ & $2(2 \mathrm{n}=3 \mathrm{x}=21)$ \\
\hline Cotia & 02 & 01 \\
São Paulo & 05 & 02 \\
Miracatu & 01 & 01 \\
\hline
\end{tabular}

stitial C-band in the short arm, which are absent in chromosome 2a. Regarding pair 3, the proximal C-band of the long arm is more distal in $3 b$ than in $3 a$ (Figures $1 b, 2$ and $5 a$ ).

\section{Karyotype of morphotype 2}

A total of 311 metaphase cells obtained from 26 regenerating blastemas from seven morphotype 2 specimens were studied. The karyotype presented $2 \mathrm{n}=3 \mathrm{x}=21$ with metacentric (1, 4 to 7), submetacentric (2) and subtelocentric (3) chromosomes. Chromosome 1 was heteromorphic in size and morphology and the triplet was comprised by two larger metacentric (1a) and a smaller submetacentric chromosome (1b). The triplet of chromosomes 3

Table 2 - Karyometric data of diploid specimens of Dolichoplana carvalhoi $(2 \mathrm{n}=2 \mathrm{x}=14$ chromosomes $)$ obtained after measurements of 13 conventionally stained mitotic metaphases.

\begin{tabular}{lccc}
\hline Chromosome & Arm ratio & $\begin{array}{c}\text { Chromosome } \\
\text { morphology }\end{array}$ & $\begin{array}{c}\text { Relative lenght } \\
(\%)\end{array}$ \\
\hline 1a & $1.4 \pm 0.2$ & $\mathrm{~m}$ & $20.4 \pm 0.8$ \\
2a and 2b & $1.8 \pm 0.2$ & sm & $17.6 \pm 0.7$ \\
3a and 3b & $4.3 \pm 0.6$ & st & $15.6 \pm 0.8$ \\
4a and 4b & $1.5 \pm 0.2$ & $\mathrm{~m}$ & $13.0 \pm 0.5$ \\
$5 \mathrm{a}$ & $1.2 \pm 0.1$ & $\mathrm{~m}$ & $12.3 \pm 0.6$ \\
6 & $1.5 \pm 0.2$ & $\mathrm{~m}$ & $10.9 \pm 0.7$ \\
$7 \mathrm{a}$ & $1.2 \pm 0.2$ & $\mathrm{~m}$ & $10.4 \pm 0.7$ \\
\hline
\end{tabular}
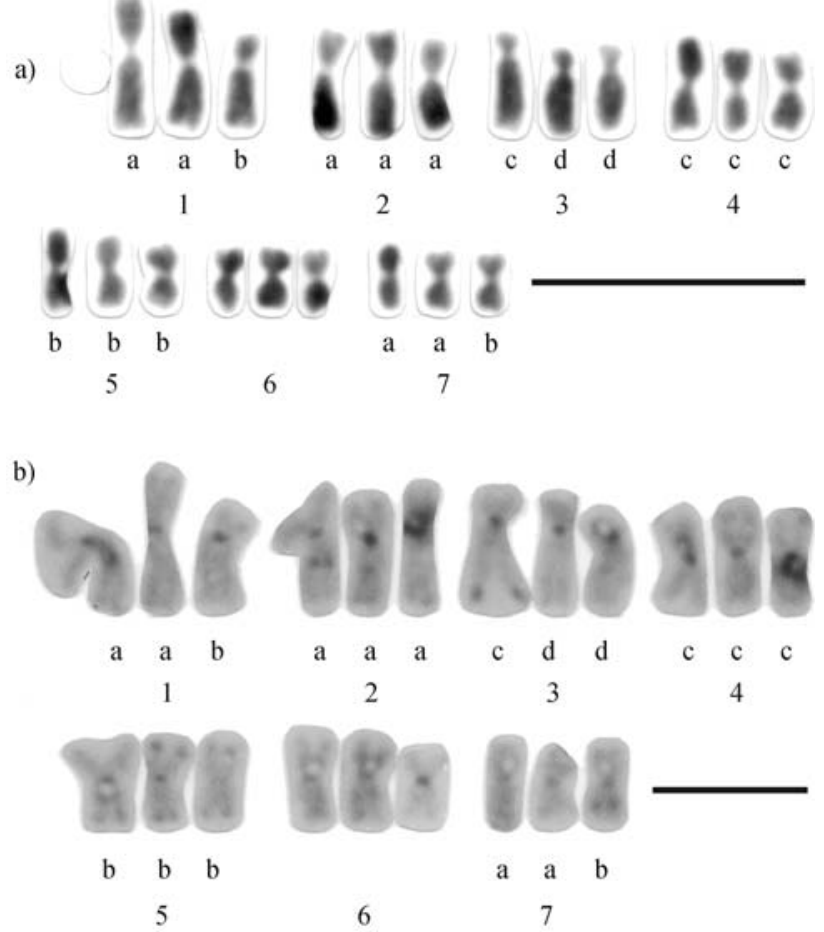

Figure 1 - Conventionally stained (a) and C-banded (b) diploid karyotypes of Dolichoplana carvalhoi $(2 \mathrm{n}=2 \mathrm{x}=14)$. Bar $10 \mu \mathrm{m}$. The letters under the chromosomes represent their variants. 
showed a size heteromorphism being composed of one larger (3c) and two smaller chromosomes (3d). Chromosome $3 \mathrm{~d}$ was similar in size to $3 \mathrm{a}$ and $3 \mathrm{~b}$ of the diploid karyotype (Table 3, Figures 3a, 4 and 5b).

$\mathrm{C}$-bands were detected in the pericentromeric areas of all chromosomes and in the telomeric and interstitial regions of some of them. All the specimens analyzed presented constitutive heterochromatin heteromorphisms in chromosomes 3 and 7. Chromosome 3a showed an evident terminal block of heterochromatin in the long arm, which was absent from $3 \mathrm{~b}$. Chromosome $7 \mathrm{~b}$ showed a distal $\mathrm{C}$-band in the long arm, which did not occur in $7 \mathrm{a}$ (Figures $3 b, 4$ and $5 b)$.

\section{Discussion}

We report herein for the first time the chromosome complement of Dolichoplana carvalhoi. Two karyotypes were detected: a diploid karyotype $(2 \mathrm{n}=2 \mathrm{x}=14$ chromosomes $)$ and a triploid karyotype $(2 \mathrm{n}=3 \mathrm{x}=21$ chromosomes), which corresponded to specimens with distinct body patterns that were called type 1 and 2, respectively. This is the first description of triploidy in a land planarian species, contrasting with the numerous reports of this kind of euploidy in Paludicola.

After conventional staining, the basic chromosome set ( $\mathrm{x}$ ) of both karyotypes ( $2 \mathrm{x}$ and $3 \mathrm{x}$ ) were similar. However, in the triploid karyotype a morphological and size heteromorphism, possibly due to chromatin loss or addition in the short arm, was observed in chromosome 1. Positive C-bands enabled the identification of heteromorphisms in chromosomes 2, 3 and 4 of the diploid and in chromosomes 3 and 7 of the triploid karyotypes.

In the diploid karyotype, the $\mathrm{C}$-banding differences in the short arm of chromosome 2 and in the long arm of chromosome 3 could be explained by paracentric inversions. Such an inversion would have changed the position of a part of the constitutive heterochromatin from the pericentromeric region of chromosome 2 (evident in the chromo-

Table 3 - Karyometric data of triploid specimens of Dolichoplana carvalhoi $(2 \mathrm{n}=3 \mathrm{x}=21$ chromosomes) obtained after measurements of 14 conventionally stained mitotic metaphases.

\begin{tabular}{lccc}
\hline Chromosome & Arm ratio & $\begin{array}{c}\text { Chromosome } \\
\text { morphology }\end{array}$ & $\begin{array}{c}\text { Relative lenght } \\
(\%)\end{array}$ \\
\hline $1 \mathrm{a}$ & $1.5 \pm 0.1$ & $\mathrm{~m}$ & $21.7 \pm 0.9$ \\
$1 \mathrm{~b}$ & $2.4 \pm 0.5$ & $\mathrm{sm}$. & $17.1 \pm 0.6$ \\
$2 \mathrm{a}$ & $1.8 \pm 0.2$ & $\mathrm{sm}$ & $14.7 \pm 0.6$ \\
$3 \mathrm{c}$ & $4.9 \pm 1.4$ & $\mathrm{st}$ & \\
$3 \mathrm{~d}$ & $4.5 \pm 0.6$ & $\mathrm{st}$ & $14.2 \pm 0.7$ \\
$4 \mathrm{c}$ & $1.2 \pm 0.1$ & $\mathrm{~m}$ & $12.3 \pm 0.8$ \\
$5 \mathrm{~b}$ & $1.2 \pm 0.1$ & $\mathrm{~m}$ & $10.6 \pm 0.5$ \\
6 & $1.2 \pm 0.1$ & $\mathrm{~m}$ & $9.4 \pm 0.6$ \\
$7 \mathrm{a}$ and $7 \mathrm{~b}$ & $1.2 \pm 0.1$ & $\mathrm{~m}$ & \\
\hline
\end{tabular}

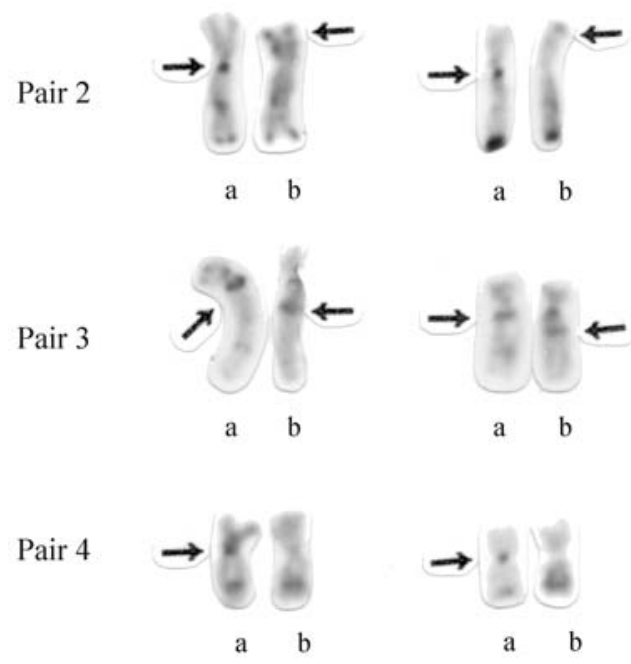

Figure 2 - C-banded heteromorphic chromosome pairs 2, 3 and 4 from different diploid specimens of Dolichoplana carvalhoi. The arrows indicate the C-banding heteromorphisms. The letters under the chromosomes represent their variants.

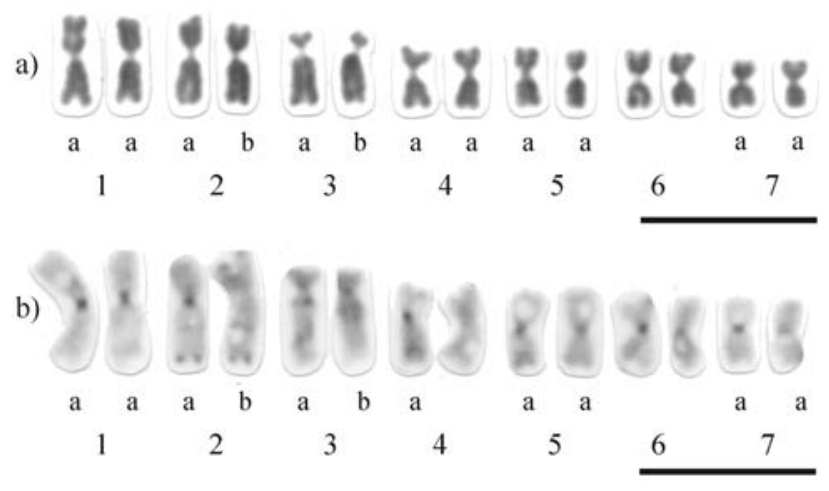

Figure 3 - Conventionally stained (a) and C-banded (b) triploid karyotypes of Dolichoplana carvalhoi $(2 \mathrm{n}=3 \mathrm{x}=21)$. Bar $10 \mu \mathrm{m}$. The letters under the chromosomes represent their variants.

some 2a) to the telomeric region of the short arm of chromosome $2 \mathrm{~b}$. The constitutive heterochromatin heteromorphisms in the interstitial band of the short arm of chromosome 2 and in the pericentromeric region of chromosome 4 could be explained by heterochromatin additions/deletions.

Chromosomes $3 \mathrm{c} / 3 \mathrm{~d}$ and $7 \mathrm{a} / 7 \mathrm{~b}$ of the triploid karyotype differed in relation to their heterochromatin content, which may be due to constitutive heterochromatin additions/deletions.

All the diploid and triploid specimens studied, which were collected in different areas, displayed the same karyotype and the same heteromorphisms. Therefore, these karyotypes seem well-established. Chromosomes of three pairs of the diploid karyotype $(3 \mathrm{a} / 3 \mathrm{~b}, 4 \mathrm{a} / 4 \mathrm{~b}$ and $5 \mathrm{a})$ were not represented in the cells of the triploid individuals. Chromosomes 1a and 7a are doubly present in the diploid and triploid individuals. It is thus possible that the triploid spec- 
imens originated from the fusion of a diploid gamete from a type 1 morphology animal with a haploid gamete of an individual of the same species, but with differences in some chromosomes. After the origin of the triploid animal, addi-

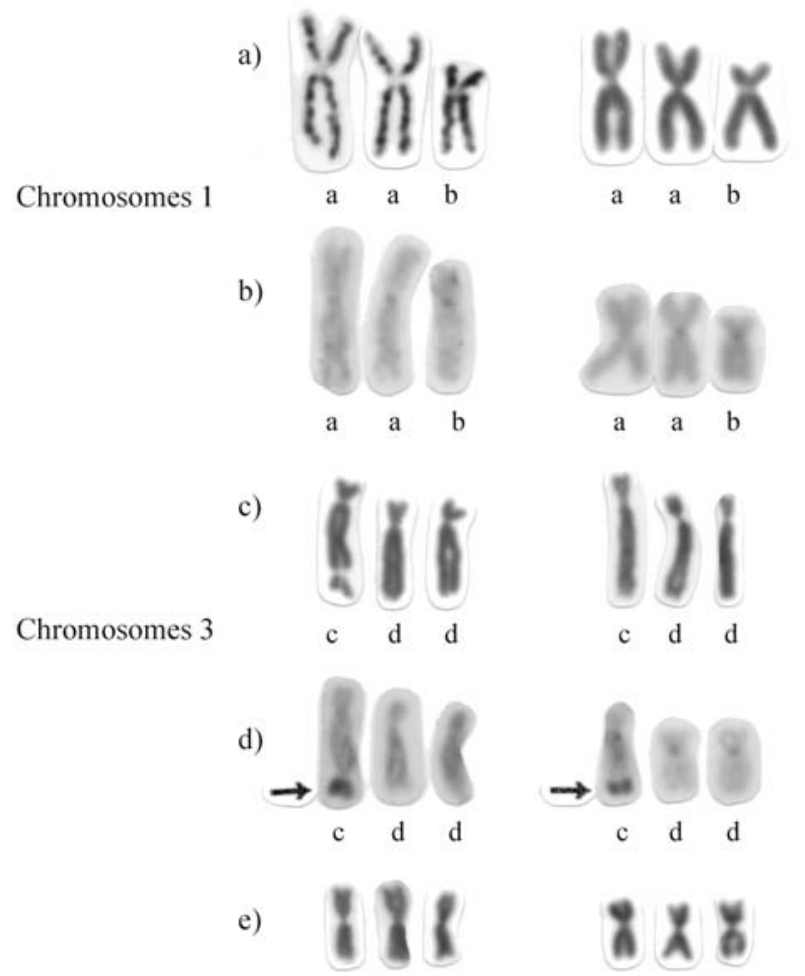

Chromosomes 7

f)
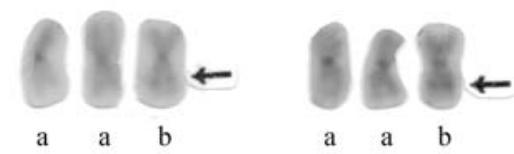

Figure 4 - Conventionally stained (a, c, e) and C-banded (b, d, f) heteromorphic chromosomes 1,3 and 7 from different triploid specimens of Dolichoplana carvalhoi. The arrows indicate the C-banding heteromorphisms. The letters under the chromosomes represent their variants.

a)

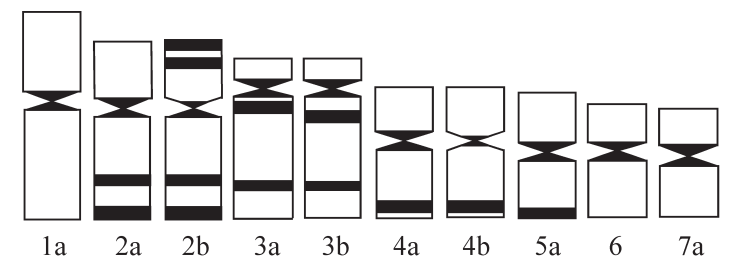

b)

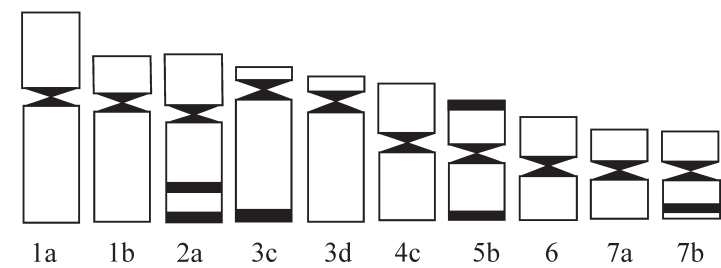

Figure 5 - Diagrammatic representation of the C-banding patterns of the chromosomes of the diploid (a) and triploid (b) karyotypes of Dolichoplana carvalhoi. tions/deletions of constitutive heterochromatin would account for the differences observed in chromosomes 3,4 and 5 .

The absence of gonopores in all the specimens with morphological pattern 2 indicates that these animals only reproduce asexually by architomy, and never sexually with cocoons deposition. This may explain how triploidy became fixed in the populations. Sexual reproduction would only be possible in polyploids with even chromosome numbers because polyploids with odd chromosome numbers are usually sterile due to meiotic irregularities (White, 1978).

It is important to emphasize that some species of freshwater planarians show polyploidy accompanied by pseudogamy. In the triploid form of Dugesia benazzii $(2 n=3 x=24)$ the cells of the female germ line undergo a chromosome duplication and become hexaploid. Such cells undergo a normal meiosis originating triploid gametes that give rise to triploid individuals through a pseudogamic development (Benazzi-Lentati, 1966). Thus, triploidy is not exclusive to asexually reproducing planarians.

The data herein presented show remarkable karyotypic differences between the specimens of Dolichoplana carvalhoi with the two morphological body patterns. It is possible that these two morphological types correspond to two different species, but further studies are needed in order to confirm this hypothesis.

\section{Acknowledgements}

The authors thank Dr. André Luiz Paranhos Perondini for helpful suggestions. We are grateful to Dr. Eudóxia Maria Froehlich for the taxonomic identification, to Miriam Romeo Silva for technical assistance and to Mr. José Domingos Batista dos Reis (in memorian) for providing some of the specimens. This study was supported in part by $\mathrm{CNPq}$ and FINEP.

\section{References}

Almeida EJC, Yamada CM and Froehlich EM (1991) Cytogenetic studies of two land-planarian species from Brazil: Geoplana marginata and Issoca rezendei (Tricladida, Terricola). Hydrobiologia 227:169-173.

Alvarez L and Almeida EJC (2002) The first record of polyploidy in a land planarian species (Geoplana burmeisteri). Caryologia 55:235-239.

Ball IR and De Vries EJ (1983) Karyological studies on land planarians (Tricladida, Terricola). Caryologia 36:195-202.

Benazzi-Lentati G (1966) Amphimixis and pseudogamy in freshwater triclads: Experimental reconstitution of polyploid pseudogamic biotypes. Chromosoma 20:1-14.

Corrêa DD (1947) Primeira Dolichoplana do Brasil. Bol Fac Fil Ci Letr Zoologia 16:63-70.

Dahm AG (1964) Karyological results from the examination of six different forms of "white Planariidae". Arkiv för Zoologi 16:488-509. 
De Vries EJ (1986) On the karyology of Dugesia gonocephala s. 1. (Turbellaria, Tricladida) from Montpellier, France. Hydrobiologia 132:251-256.

Froehlich CG (1967) A contribution to the zoogeography of the Neotropical land planarians. Acta Zoologica Lilloana 23:153-162.

Garcia LR, Alvarez L and Almeida EJC (1998) Estudo citogenético com indicação de mixoploidia em uma espécie de planária terrestre: Pasipha pasipha. Proceedings of the $44^{\text {th }}$ Congresso Nacional de Genética, Águas de Lindóia, SP, Brazil, pp 56.

Gourbault N (1981) The karyotypes of Dugesia species from Spain (Turbellaria, Tricladida). Hydrobiologia 84:45-52.

Kawakatsu M, Oki I, Tamura S and Yamayoshi T (1985) Reexamination of freshwater planarians found in tanks of tropical fishes in Japan, with a description of a new species, Dusegia austroasiatica sp nov. (Turbellaria, Tricladida, Paludicola). Bull Biogeogr Soc Japan 40:1-19.

Le Moigne A (1962) Étude de formules chromosomiques de quelques Polycelis (Turbellariés, Triclades) de la région parisienne. Bulletin de la Societé Zoologique de France 87:259-270.

Levan A, Fredga K and Sandberg AA (1964) Nomenclature for centromeric position on chromosomes. Hereditas 52:201220.

Minelli A (1977) Microplana mahnerti n. sp., a new Terrestrial Planarian from Jura Mts (Turbellaria, Tricladida, Rhynchodemidae). Revue Suisse Zool 84:173-176.
Oki I, Tamura S, YamayoshI T and Kawakatsu M (1981) Karyological and taxonomic studies of Dugesia japonica Ichikawa et Kawakatsu in the Far East. Hydrobiologia 84:53-68.

Oki I, Tamura S, Ogren RE and Kawakatsu M (1988) Karyological and taxonomic studies of three species of the genus Bipalium from Japan and the United States and Platydemus manokwari from the Philippines. In: Ax, Ehlers and SopottEhlers (eds) Free-Living and Symbiotic Plathelminthes. Gustav Fisher Verlag, New York, pp 139-143.

Puccinelli I and Benazzi M (1985) Osservazione sulla ecologia e cariologia della planaria Dugesia brigantii. Atti Soc Tosc Sci Nat, Mem Serie B 92:283-289.

Ribas M, Riutort M and Baguña J (1989) Morphological and biochemical variation in populations of Dugesia $(G)$ tigrina (Tubellaria, Tricladida, Paludicola) from the western Mediterianean: Biogeographical and taxonomic implications. J Zool Lond 218:609-626.

Sumner AT (1972) A rapid technique for demonstrating centromeric heterochromatin. Exptl Cell Res 75:304-306.

Tamura S (1986) Variation in karyotypes of Dugesia japonica japonica (Turbellaria) from Osaka Prefecture, Central Japan. Hydrobiologia 132:234-249.

Teshirogi W, Ni-Imura F and Ishida S (1991) Further survey of chromosomal polymorphisms in the freshwater planarian Polycelis auriculata. Hydrobiologia 227:147-156.

White MJD (1978) Modes of speciation. W.H. Freeman, San Francisco, 455 pp.

Associate Editor: Yatiyo Yonenaga-Yassuda 